Research Article

\title{
Cement-Lime-Fly Ash Bound Macadam Pavement Base Material with Enhanced Early-Age Strength and Suppressed Drying Shrinkage via Incorporation of Slag and Gypsum
}

\author{
Cheng Ju, ${ }^{1,2,3}$ Yushi Liu $\mathbb{D}^{1,2,3}$ Zhenyun Yu, ${ }^{1}$ and Yingzi Yang $\mathbb{D}^{1,2,3}$ \\ ${ }^{1}$ School of Civil Engineering, Harbin Institute of Technology, Harbin 150090, China \\ ${ }^{2}$ Key Lab of Structures Dynamic Behavior and Control of the Ministry of Education, Harbin Institute of Technology, \\ Harbin 150090, China \\ ${ }^{3}$ Key Lab of Smart Prevention and Mitigation of Civil Engineering Disasters of the Ministry of Industry and \\ Information Technology, Harbin Institute of Technology, Harbin 150090, China \\ Correspondence should be addressed to Yushi Liu; liuyushi@hit.edu.cn and Yingzi Yang; yzyang@hit.edu.cn
}

Received 7 June 2019; Revised 30 August 2019; Accepted 2 November 2019; Published 29 November 2019

Academic Editor: Carlos Chastre

Copyright (c) 2019 Cheng Ju et al. This is an open access article distributed under the Creative Commons Attribution License, which permits unrestricted use, distribution, and reproduction in any medium, provided the original work is properly cited.

In this study, a novel cement-lime-fly ash bound macadam (CLFBM) as pavement base material was designed by incorporating Portland cement, dihydrate gypsum $\left(\mathrm{CaSO}_{4} \cdot 2 \mathrm{H}_{2} \mathrm{O}\right)$, and ground granulated blast furnace slag (GGBS) into the lime-fly ash bound macadam (LFBM) for the purpose of the early opening to traffic. The multifactors orthogonal test method was used to evaluate the effects of Portland cement, dihydrate gypsum, and GGBS on the early-age strength of CLFBM. Moreover, the compressive and flexural strengths at 28 days as well as the drying shrinkage development in 56 days were investigated. By conducting the comprehensive analysis for the better mechanical properties and the lowest drying shrinkage, Portland cement: dihydrate gypsum:lime:fly ash:GGBS: gravels =2:1:6:5.6:8.4:80 is determined as the optimal mix proportion of CLFBM. In addition, scanning electron microscope (SEM) results confirmed the formation of a large number of ettringite and C-S-H gels, providing a powerful support for the enhanced early-age strength and suppressed drying shrinkage of CLFBM.

\section{Introduction}

With the development of economy, the highway traffic volume is growing rapidly in China $[1,2]$. In order to adapt this tendency, the semirigid road base materials such as lime-fly ash bound macadam (LFBM) have been widely used in highway construction because of their excellent workability and economic benefits [3-6]. The LFBM is comprised of lime, fly ash, and gravels [5], in which the lime can enhance the pozzolanic reaction of fly ash, increasing the earlyage and long-term strengths $[7,8]$. However, due to the low pozzolanic reactivity of fly ash at early age, wet curing at least one week need to be guaranteed to meet the requirement of early-age strength of LFBM, and if the ambient temperature is lower than $20^{\circ} \mathrm{C}$, the wet curing time required should reach two weeks or more [9]. This severely limits the early opening to traffic. Therefore, it is urged to improve the early-age strength of LFBM.

Cement, with fast hydration reaction, should be of help to increase the early-age strength of LFBM [7]; however, using more cement always indicates the higher drying shrinkage of cementitious materials [10,11]. Plenty of researches confirm that the drying shrinkage in pavement base materials is the culprit of the deformation and cracking of the asphalt pavement $[7,12]$. Clearly, the drying shrinkage is also a vital indicator for LFBM [13], thus the cement content should be controlled and optimized. The replacement of cement by use of cementitious materials (SCMs) has been widely studied [14]. Cement can partly be replaced by fly ash, slag, or other mineral admixtures in cement-based materials, which can 
improve the strength and durability [15]. Moreover, this will also lead to additional benefits in terms of cost savings, energy conservation, protection of nonrenewable resources, etc [16]. Remarkably, the pozzolanic activity of ground granulated blast furnace slag (GGBS) is superior to fly ash $[17,18]$, thus it can be expected to further improve the early-age strength of LFBM when GGBS is used to replace a part of fly ash; the use of chemical activator approaches can promote the pozzolanic reaction of fly ash $[19,20]$, increasing the early strength of LFBM, wherein the alkali activation and sulfate activation are the most-used chemical activating methods [21-23]. On the basis of satisfying the early-age strength and reducing the drying shrinkage of LFBM, using GGBS and sulfate activator may be a good option because of the main hydration product activated by sulfate being ettringite. The formation of the ettringite is accompanied by volume expansion $[24,25]$, which may be able to compensate the drying shrinkage.

In this work, the dihydrate gypsum $\left(\mathrm{CaSO}_{4} \cdot 2 \mathrm{H}_{2} \mathrm{O}\right)$ was selected as the sulfate activator to improve early-age strength and decrease drying shrinkage. The cement as additive agent and GGBS as replacement of fly ash were also used to enhance the early-age strength of LFBM. The effects of dihydrate gypsum, cement, and GGBS on the early-age strength were evaluated by the significance level of the statistics based on the multifactors orthogonal test. And referring to the results of drying shrinkage, the novel pavement base materials, cement-lime-fly ash bound macadam (CLFBM) with optimum mix proportion, were presented. In addition, the microstructure characterizations of CLFBM were conducted as well.

\section{Experimental Program}

2.1. Materials. The chemical compositions of P.O 42.5 Portland cement, lime, fly ash, ground granulated blast furnace slag (GGBS), and dihydrate gypsum $\left(\mathrm{CaSO}_{4} \cdot 2 \mathrm{H}_{2} \mathrm{O}\right.$, purity $\geq 99.0 \%$ ) are shown in Table 1 . The physical properties of cement are given in Table 2. The particle size distribution of gravels is shown in Table 3. In Table 2, boiling test methods were used to measure the soundness of cement according to the national standard "Test methods for water requirement of normal consistency, setting time and soundness of the portland cements (GB/T 1346-2011)"; the Blaine method was used to measure the specific surface area of cement according to the national standard "Testing method for specific surface of cement (GB/T 8074-2008)"; compressive strength of standard cement mortar was measured by the method of testing cements-determination of strength (GB/T 17671-1999). In Table 3, the screening of the aggregate gradation was measured in accordance with the national standard "Pebble and crushed stone for construction (GB/T 14685-2011).”

\subsection{Optimal Design and Preparation of CLFBM.} According to "Pavement Base Technical Specifications for Construction" (JTJ 034-2000, China), the reasonable composition of the lime-fly ash bound macadam (LFBM) with fly ash, lime, and gravels with an optimized particle size distribution was determined. The LFBM consisted of $6 \mathrm{wt} \%$ lime, $14 \mathrm{wt}$ $\%$ fly ash, and $80 \mathrm{wt} \%$ gravels. In order to obtain the highperformance cement-lime-fly ash bound macadam (CLFBM) with higher early-age strength and lower drying shrinkage, the dihydrate gypsum, cement, and GGBS were used as additive materials. The recommended cement content is given in the relevant provision of "Pavement Base Technical Specifications for Construction" (JTJ 0342000, China). Cement is added to improve the early-age strength. Considering the economic cost, the additive amount of cement is determined to be $2 \sim 4 \mathrm{wt} \%$. Fly ash is less active than slag. To improve early-age strength, slag is used to replace the part of fly ash, in which the replacement ratio is $0 \sim 60 \mathrm{wt} \%$. Gypsum as sulfate activator is used to improve the early-age strength. Meanwhile, the ettringite formed by reaction can compensate for the drying shrinkage of pavement base material. Referring to the relevant research on the strength improvement of the cement-based material with high volume fly ash, the additive amount of gypsum is determined to be $1 \sim 5 \mathrm{wt} \%$ $[26,27]$. The orthogonal test designed by Statistical Product and Service Solutions software (SPSS) was performed. The experiment was organized as an $\mathrm{L}_{9}\left(3^{4}\right)$ orthogonal array, as listed in Table 4 . To be specific, cement was added in the LFBM at $2 \mathrm{wt} \%, 3 \mathrm{wt} \%$, and $4 \mathrm{wt} \%$, by weight of LFBM; GGBS was used to replace the partial fly ash, and the replacement levels were $0 \%, 30 \mathrm{wt} \%$, and $60 \mathrm{wt} \%$, by weight of fly ash; the additive amount of dihydrate gypsum used as activator was $1 \mathrm{wt} \%, 3 \mathrm{wt} \%$, and $5 \mathrm{wt} \%$, by total mass of lime, fly ash, and GGBS. The 3-day compressive strength and drying shrinkage value of CLFBM were chosen to evaluate the effects of the three factors including dihydrate gypsum, cement, and GGBS.

Sample preparation was as follows: as shown in Table 5, nine groups of samples with different mix proportion were determined via the $\mathrm{L}_{9}\left(3^{4}\right)$ orthogonal array. For each sample, the maximal dry density and optimum water proportion were gained with a tamping test which was conformed to the test method T0804-94 specification of Ministry of Transport of the People's Republic of China. The detailed measurement method is as follows: the heavy compaction instrument with the size of $\Phi 15.2 \mathrm{~cm} \times 17.0 \mathrm{~cm}$ was applied, and it was equipped with a $4.5 \mathrm{~kg}$ hammer. Tested material with the mass of $33 \mathrm{~kg}$ was divided into 6 parts by the quartering method, and the air-dry mass of each part was about $5.5 \mathrm{~kg}$. Six different water proportions were also designed, with a difference of $1 \%$ between each other. The prepared sample with the mass of $1.8 \mathrm{~kg}$ was poured into the heavy compaction instrument, and then the first layer of sample was compacted with the compaction times of 98 . During the compaction process, the hammer should fall straight and freely with a drop height of $45 \mathrm{~cm}$, and the imprints of the hammer were evenly distributed on the sample surface. The above procedure was repeated for the compaction of the remaining two layers of the sample. After compaction, the sample was pushed out from the cylinder with a bulldozer, and the water proportion is measured from the center of the sample. The dry density of the sample after compaction is calculated with equation (1): 
TABle 1: The chemical compositions of raw materials (wt\%).

\begin{tabular}{lcccc}
\hline Oxide (\%) & Cement & Lime & Fly ash & GGBS \\
\hline $\mathrm{LOI}$ & 2.16 & - & 3.30 & 0.25 \\
$\mathrm{CaO}$ & 62.24 & 63.7 & 3.21 & 35.50 \\
$\mathrm{SiO}_{2}$ & 20.89 & - & 49.8 & 31.85 \\
$\mathrm{Al}_{2} \mathrm{O}_{3}$ & 5.44 & 3.0 & 29.5 & 16.69 \\
$\mathrm{MgO}$ & 1.71 & - & - & 9.5 \\
$\mathrm{Fe}_{2} \mathrm{O}_{3}$ & 3.96 & - & - & 0.16 \\
$\mathrm{FeO}$ & - & - & 1.41 & 0.76 \\
$\mathrm{TiO}_{2}$ & - & - & - & 0.64 \\
$\mathrm{SO}_{3}$ & 2.65 & & - \\
\hline
\end{tabular}

TABle 2: The physical properties of cement.

\begin{tabular}{|c|c|c|c|c|c|}
\hline \multirow[t]{2}{*}{ Soundness } & \multirow[t]{2}{*}{ Specific surface area $\left(\mathrm{m}^{2} / \mathrm{kg}\right)$} & \multicolumn{2}{|c|}{$\begin{array}{c}\text { Compressive } \\
\text { strength }(\mathrm{MPa})\end{array}$} & \multicolumn{2}{|c|}{$\begin{array}{c}\text { Flexural strength } \\
(\mathrm{MPa})\end{array}$} \\
\hline & & $3 \mathrm{~d}$ & $28 \mathrm{~d}$ & $3 \mathrm{~d}$ & $28 \mathrm{~d}$ \\
\hline (Boiling method) qualified & $>300$ qualified & 16.7 & 46.1 & 4.9 & 7.4 \\
\hline
\end{tabular}

TABLE 3: The particle size distribution of gravels.

\begin{tabular}{lcccccccc}
\hline \multirow{2}{*}{ Gravel particle size } & \multicolumn{7}{c}{ The mass percentage of undersize (\%) } \\
& $31.5 \mathrm{~mm}$ & $19 \mathrm{~mm}$ & $9.5 \mathrm{~mm}$ & $4.75 \mathrm{~mm}$ & $2.36 \mathrm{~mm}$ & $1.18 \mathrm{~mm}$ & $0.6 \mathrm{~mm}$ & $0.075 \mathrm{~mm}$ \\
\hline $10 \sim 30 \mathrm{~mm}$ & 100 & 79.8 & 1.2 & 0.5 & 0 & 0 & 0 & 0 \\
$5 \sim 10 \mathrm{~mm}$ & 100 & 100 & 95.2 & 44.1 & 5.7 & 2.9 & 0 & 0 \\
$0 \sim 5 \mathrm{~mm}$ & 100 & 100 & 100 & 99.7 & 84.4 & 63.9 & 39.6 & 8.7 \\
\hline
\end{tabular}

TABLE 4: Factors and levels for orthogonal experiment.

\begin{tabular}{lccc}
\hline Levels & & Factors & \\
& Cement content (wt \%) & Gypsum content (wt\%) & GGBS replacement (wt\%) \\
\hline 1 & 2.0 & 1.0 & 30 \\
2 & 3.0 & 3.0 & 60 \\
3 & 4.0 & 5.0 & 30 \\
\hline
\end{tabular}

TABLE 5: Orthogonal experiment arrangements and results.

\begin{tabular}{lccccc}
\hline Sample & $\begin{array}{c}\text { Cement content } \\
(\mathrm{wt} \%)\end{array}$ & $\begin{array}{c}\text { Fypsum content } \\
(\mathrm{wt} \%)\end{array}$ & $\begin{array}{c}\text { GGBS replacement } \\
(\mathrm{wt} \%)\end{array}$ & $\begin{array}{c}\text { 3-day compressive strength } \\
(\mathrm{MPa})\end{array}$ & $\begin{array}{c}56 \text {-day drying shrinkage strain } \\
\left(10^{-6}\right)\end{array}$ \\
\hline $\mathrm{N}_{1}$ & 2.0 & 1.0 & 0 & 0.58 & -555 \\
$\mathrm{~N}_{2}$ & 2.0 & 3.0 & 30 & 1.01 & -450 \\
$\mathrm{~N}_{3}$ & 2.0 & 5.0 & 60 & 2.23 & -312.5 \\
$\mathrm{~N}_{4}$ & 3.0 & 1.0 & 30 & 1.38 & -490 \\
$\mathrm{~N}_{5}$ & 3.0 & 3.0 & 60 & 1.91 & -475 \\
$\mathrm{~N}_{6}$ & 3.0 & 5.0 & 0 & 1.80 & -530 \\
$\mathrm{~N}_{7}$ & 4.0 & 1.0 & 60 & 2.34 & -540 \\
$\mathrm{~N}_{8}$ & 4.0 & 3.0 & 0 & 1.53 & -637.5 \\
$\mathrm{~N}_{9}$ & 4.0 & 5.0 & 30 & 2.13 & -675 \\
\hline
\end{tabular}

$$
\rho_{d}=\frac{\rho}{1+0.01 w}
$$

where $\rho_{d}$ and $\rho$ are dry density and wet density with the unit of $\mathrm{g} / \mathrm{cm}^{3}$, respectively, and $w$ is water proportion with the unit of $\%$.
The relationship curve between dry density and water proportion was drawn with the dry density as the vertical coordinate and the water proportion as the horizontal coordinate. The peak coordinate point on the curve was determined to be the maximum dry density and optimum water proportion values, respectively. 
In accordance with the determined maximal dry density and optimum water proportion, the compressive strength test specimens were formed with $\Phi 150 \mathrm{~mm} * 150 \mathrm{~mm}$ steel molds, and the flexural strength and drying shrinkage test specimens were cast in $100 \mathrm{~mm} * 100 \mathrm{~mm} * 400 \mathrm{~mm}$ plastic molds. To be specific, the $150 \mathrm{~mm} * 150 \mathrm{~mm}$ cylinder iron mold filled with CLFBM mixture is put on the pressure machine for static compression molding. The loading rate is $2 \sim 4 \mathrm{MPa} / \mathrm{s}$, and the final loading force is $400 \mathrm{kN}$. The cuboid mold with the size of $100 \mathrm{~mm} * 100 \mathrm{~mm} * 400 \mathrm{~mm}$ filled with CLFBM mixture is placed on the vibration table to be vibrated. Meanwhile, a $20 \mathrm{~kg}$ iron block with the bottom size of $100 \mathrm{~mm} * 400 \mathrm{~mm}$ was used to compact the mixture.

2.3. Compressive Strength. The compressive strength tests are conformed to the unconfined compression test method formulated by the criteria, "Technical Specifications for Construction of Pavement Base (JTJ 034-2000, China)." The cylinders were cured in the airproof plastic bags at $20 \pm 2{ }^{\circ} \mathrm{C}$, and on the last day of the curing period, the cylinders were steeped into water for $24 \mathrm{~h}$ before testing. Three cylinders of $\Phi 150 \mathrm{~mm} * 150 \mathrm{~mm}$ were tested for each mix proportion of CLFBM for 3 days, 7 days, and 28 days. The strength results are an average of results for the three specimens.

2.4. Flexural Strength. The flexural strength tests refer to the three point bending test which was carried out at loading rate of $0.05 \mathrm{~mm} / \mathrm{min}$. The beam specimens were cured in the airproof plastic bags at $20 \pm 2^{\circ} \mathrm{C}$, and on the last day of the curing period, the beam specimens were submerged in water for $24 \mathrm{~h}$ before testing. Three beam specimens of $100 \mathrm{~mm} *$ $100 \mathrm{~mm} * 400 \mathrm{~mm}$ were tested for each mix proportion of CLFBM for 28 days. Sample flexural strength can be calculated as follows:

$$
F=\frac{3 P L}{2 b d^{2}},
$$

where $P$ is the maximum loading force, $\mathrm{N} ; L$ is the support span length, $\mathrm{mm} ; b$ is the width of sample, $\mathrm{mm}$; and $d$ is the sample depth, $\mathrm{mm}$.

2.5. Drying Shrinkage Measurement. The beam specimens of $100 \mathrm{~mm} * 100 \mathrm{~mm} * 400 \mathrm{~mm}$ were demolded over a $48-\mathrm{h}$ period and immediately stored in a dry room at a constant temperature of $20^{\circ} \mathrm{C}$ and $50 \%$ relative humidity (RH). Three specimens were cast for each mix proportion of CLFBM and for drying shrinkage test. The length evolutions at the ages of $2,4,6,8,10,12,14,16,18,20,24,28,42$, and 56 days were determined by using a self-designed shrinkage measuring instrument shown in Figure 1. The micrometer caliper fixed on one end of the half-round fixed frame was used to measure the length change of the beam specimen. Finally, all drying shrinkage results were described as drying shrinkage strain of the specimen through the following equations:

$$
\varepsilon_{d}=\frac{\Delta L}{L}
$$

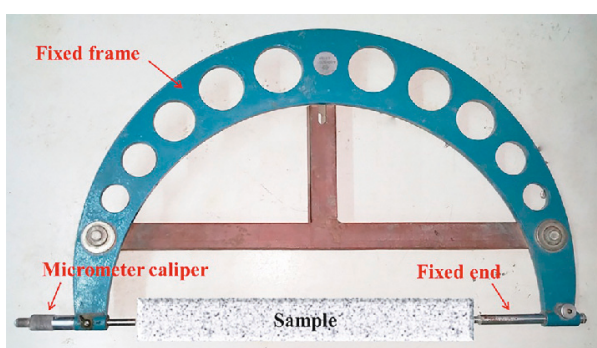

FIGURE 1: Schematic of the self-designed shrinkage measuring instrument.

where $\varepsilon_{d}$ is the drying shrinkage strain $\left(\times 10^{-6}\right) ; \Delta L$ represents the length change value of the specimen, $\mathrm{mm}$; and $L$ denotes the overall length of sample, $\mathrm{mm}$.

2.6. Microstructure Analysis. The microstructure observation samples were collected from the binders within specimens of CLFBM at 3 days and 28 days, which were dried with vacuum and covered by a gold layer. The microstructures of the samples were studied with the field emission scanning electron microscopy (FE-SEM, Quanta 200F, FEI, Holand).

\section{Results and Discussion}

3.1. Mix Optimization of CLFBM Based on Early-Age Strength. As shown in Table 4, the roles of cement, dihydrate gypsum, and GGBS in contributing to improving the early-age strength have been discussed in details. The experiment arrangements and results by orthogonal test are listed in Table 5. Figure 2 shows the compressive strength of samples $\mathrm{N}_{1}-\mathrm{N}_{9}$ at 3,7 , and 28 days. It can be seen from Figure 2 that the compressive strength of CLFBM is increased with increasing curing period. The evaluation of compressive strength is the most direct reference value as required in the relevant provision of "Pavement Base Technical Specifications for Construction" (JTJ 034-2000, China). In order to improve the early-age strength of pavement base materials as significantly as possible, the compressive strength of CLFBM at 3 days should be a major consideration because of the importance of the early opening to traffic [28]. Thus, the 3-day compressive strength is presented in Table 5 as the evaluation indicator.

To investigate the significance of the three factors and the trends in increasing the early-age strength of CLFBM for each based on the 3-day compressive strength, the analysis of variance (ANOVA) and factor-level trend of orthogonal test are carried out using SPSS, and the results are presented in Table 6 and Figure 3, respectively.

Table 6 indicates that the significance of the three factors with respect to the 3-day compressive strength is in the order: GGBS replacement $>$ cement content $\approx$ gypsum content. Moreover, the GGBS, cement, and dihydrate gypsum play a positive role in the improvement of 3-day compressive strength, as shown in factor-level trend chart (Figure 3). Since the $P$ value of GGBS replacement is 0.048 , which is lower than 0.05 , the influence of GGBS replacing fly ash on 


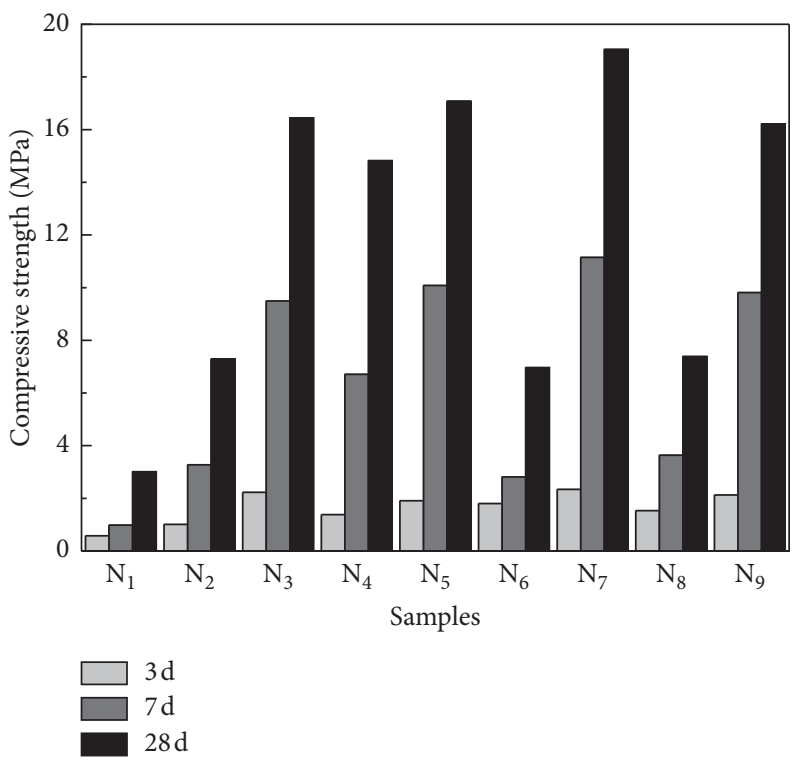

FIgURE 2: The compressive strength at 3,7 , and 28 days.

TABLE 6: Tests of between-subjects effects.

\begin{tabular}{lcccc}
\hline Source & Type III sum of squares & df & Mean square & $F$ \\
\hline Corrected model & $2.713^{\mathrm{a}}$ & 6 & 0.452 & 14.761 \\
Intercept & 24.701 & 1 & 24.701 & 806.341 \\
Cement content & 0.799 & 2 & 0.400 & 13.046 \\
Gypsum content & 0.712 & 2 & 0.356 & 0.065 \\
GGBS replacement & 1.202 & 2 & 0.601 & 0.071 \\
Error & 0.061 & 2 & 0.031 & 0.079 \\
Total & 27.475 & 9 & & 0.048 \\
Corrected total & 2.774 & 8 & & 19.620 \\
\hline
\end{tabular}

${ }^{\mathrm{a}} R$ squared $=0.978$ (adjusted $R$ squared $=0.912$ ); dependent variable: 3 -day compressive strength $(\mathrm{MPa})$.

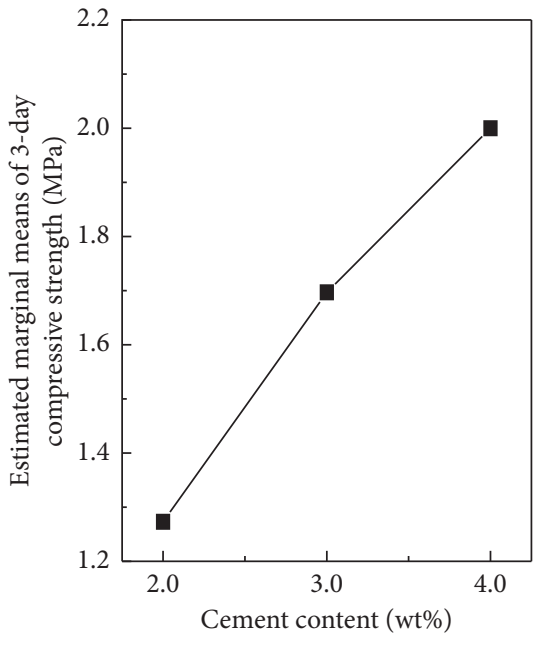

(a)

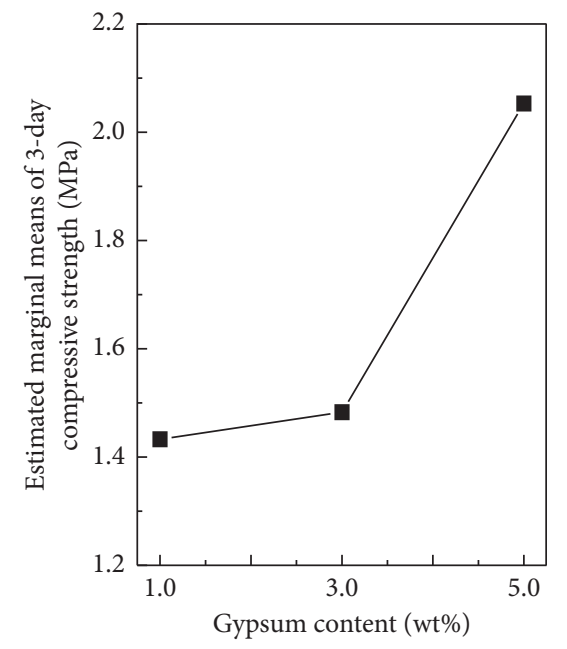

(b)

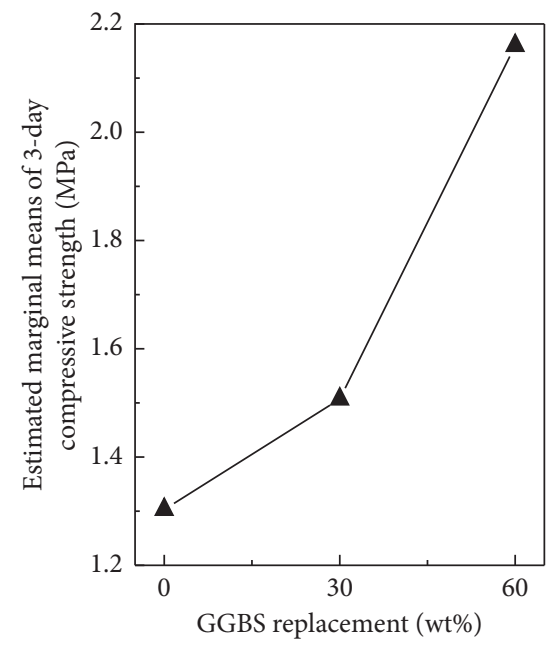

(c)

FIGURE 3: Factor-level trend chart. (a) Cement content, (b) gypsum content, and (c) GGBS replacement.

3-day compressive strength is significant. The $P$ values of 0.071 and 0.079 for cement content and gypsum content are greater than 0.05 and less than 0.1 , possessing a relatively large effect on 3-day compressive strength of CLFBM. Obviously, the influence degree of GGBS on the 3-day compressive strength of CLFBM is well above those of 
cement and dihydrate gypsum. The dosage of the dihydrate gypsum is much less than that of cement in CLFBM (dihydrate gypsum by weight of cementing material, while cement by weight of LFBM), whereas the influence degree of dihydrate gypsum on 3-day compressive strength is nearly the same as that of cement, which indicates dihydrate gypsum is very helpful for early-age strength improvement.

However, on the premise of ensuring 3-day early-age strength, the 28-day compressive strength and flexural strength should also be concerned about. It is observed from Figure 2 that the 28-day compressive strength of samples $\mathrm{N}_{3}$, $\mathrm{N}_{5}, \mathrm{~N}_{7}$, and $\mathrm{N}_{9}$ is much higher compared with the samples with other mix proportions. Moreover, this phenomenon is also found in the results of 28-day flexural strength shown in Figure 4. Considering the mix proportion of samples, as shown in Table 5 , it is found that samples $\mathrm{N}_{3}, \mathrm{~N}_{5}$, and $\mathrm{N}_{7}$ have the maximum replacement level of GGBS (60 $\mathrm{wt} \%)$. As for the sample $\mathrm{N}_{9}$, because of the maximum cement content and more GGBS replacement amount, its 28-day compressive strength is higher as well. In addition, of all the samples of CLFBM, the 28-day compressive strength of the samples $\mathrm{N}_{1}, \mathrm{~N}_{6}$, and $\mathrm{N}_{8}$ without GGBS is lower (their earlyage strength is also lower, and the strength development tends to be slow).

From the above analysis and orthogonal test result, it is not difficult to get the conclusion that the GGBS replacement plays a leading role in the strength improvement of CLFBM at various curing periods. Therefore, it is suggested that there should be a maximum GGBS replacement level of $60 \mathrm{wt} \%$ in the CLFBM. However, as revealed by the orthogonal test result, the dihydrate gypsum has almost the same effect with cement in terms of enhancing the early-age strength of CLFBM. Thus, within the acceptable range of early-age strength, dihydrate gypsum could be used to replace part of cement in the CLFBM due to the low cost of gypsum. That is, it is suggested that there should be a minimum cement content of $2.0 \mathrm{wt} \%$ and maximum gypsum content of $5.0 \mathrm{wt}$ $\%$ in the CLFBM. To sum up the above arguments, the samples $\mathrm{N}_{3}$ is determined as the CLFBM pavement base materials with optimal mix proportion. By mathematical conversion, the mix proportion of the sample $\mathrm{N}_{3}$ is equivalent to that cement: dihydrate gypsum : lime : fly ash : GGBS : gravel $=2: 1: 6: 5.6: 8.4: 80$.

The 7-day compressive strength of LFBM is required to not be lower than $0.8 \sim 1.1 \mathrm{MPa}$ in the criteria, "Technical Specifications for Construction of Pavement Base (JTJ 0342000, China)." As to the CLFBM pavement base materials, the 3-day compressive strength of sample $\mathrm{N}_{3}$ has reached $2.23 \mathrm{MPa}$, which obviously, meets the requirement of the early-age strength.

3.2. Drying Shrinkage Assessment for the Further Determination of the Optimum Proportion of CLFBM. Drying shrinkage is considered as a main reason for the structure destruction of pavement base material [29-31]. The serious drying shrinkage will also lead to the crack generation of the asphalt pavement laid on CLFBM. Therefore, apart from the early-age strength, the drying

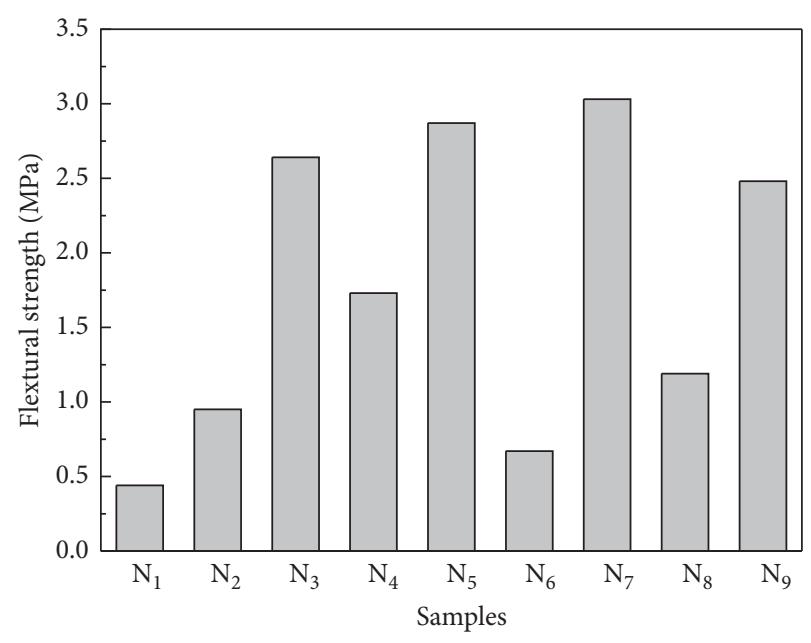

Figure 4: The 28-day flexural strength of CLFBM.

shrinkage is another key point for CLFBM performance. Figure 5 demonstrates the drying shrinkage development of samples $\mathrm{N}_{1}-\mathrm{N}_{9}$ during 56 curing days. It can be seen from Figure 5 that the drying shrinkage of samples $\mathrm{N}_{7}, \mathrm{~N}_{8}$, and $\mathrm{N}_{9}$ is evident before 14 days. And the drying shrinkage strain of the three samples maintains continued increase from 28 days to 56 days, as shown in Figure 5. Especially for samples $\mathrm{N}_{8}$ and $\mathrm{N}_{9}$, the drying shrinkage strain reaches up to $-637.5 \times 10^{-6}$ and $-675 \times 10^{-6}$ at 56 days, respectively. Obviously, the addition of cement is mainly responsible for the increasing drying shrinkage of CLFBM. However, it can be noticed from Figure 5 that the drying shrinkage strain of sample $\mathrm{N}_{3}$ keeps to be a minimum before 56 days and tends to be constant from 28 days to 56 days $\left(-275 \times 10^{-6}\right.$ at 28 days and $-312.5 \times 10^{-6}$ at 56 days). This indicates that the sample $\mathrm{N}_{3}$ can be identified as the CLFBM pavement base material.

In order to investigate the influence of the three factors (cement content, gypsum content and GGBS replacement) and the trends of the drying shrinkage strain of samples for each factor, the analysis of factor-level trend of orthogonal test were carried out using SPSS, and the results are shown in Figure 6. It can be noticed from Figure 6 that the drying shrinkage strain of CLFBM increases by $178.3 \times 10^{-6}$ when the cement content increases from $2.0 \mathrm{wt} \%$ to $4.0 \mathrm{wt} \%$. Moreover, as the gypsum content is increased from $1.0 \mathrm{wt} \%$ to $5.0 \mathrm{wt} \%$, the drying shrinkage strain of CLFBM has been decreased by about $22.5 \times 10^{-6}$. Besides, the drying shrinkage strain is reduced from $-574.2 \times 10^{-6}$ to $-538.3 \times 10^{-6}$ and $-442.5 \times 10^{-6}$ as the replacement level of GGBS is increased from 0 to 30 and $60 \mathrm{wt} \%$. Considering the results displayed in Figure 6, gypsum content and GGBS replacement are crucial for inhibiting the drying shrinkage strain of CLFBM. In the CLFBM, the major component of lime, $\mathrm{CaO}$ reacts firstly with water $\left(\mathrm{H}_{2} \mathrm{O}\right)$ to yield $\mathrm{Ca}(\mathrm{OH})_{2}$. Under alkaline conditions, $\mathrm{SiO}_{2}$ and $\mathrm{Al}_{2} \mathrm{O}_{3}$ in vitreous of GGBS and of fly ash are dissolved and to react with $\mathrm{Ca}^{2+}$ to create calcium silicate hydrate and hydrated calcium aluminate [32]. Moreover, with the condition of the existence of dihydrate gypsum $\left(\mathrm{CaSO}_{4} \cdot 2 \mathrm{H}_{2} \mathrm{O}\right)$, the ettringite $(\mathrm{AFt})$ is also formed 


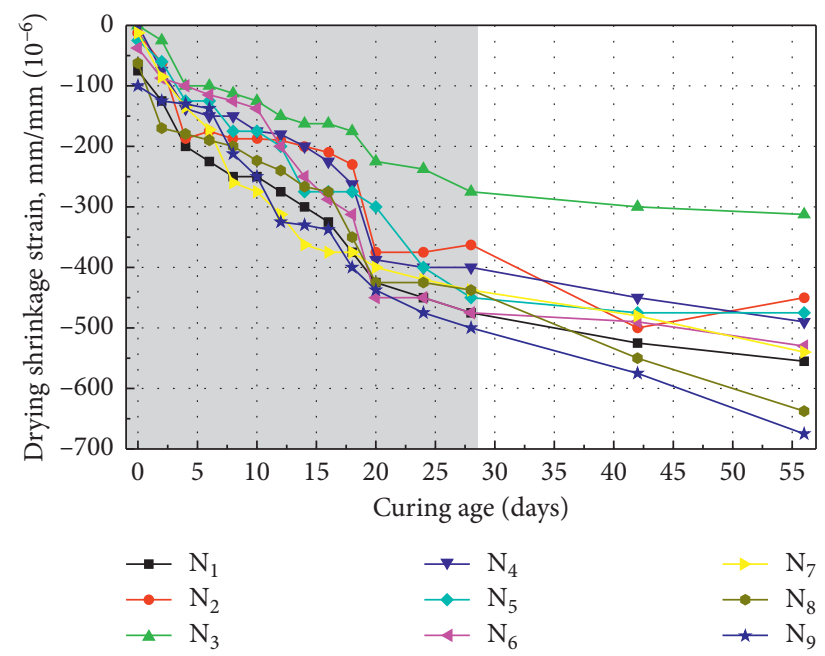

FIgURE 5: The drying shrinkage development with 56-day curing ages.

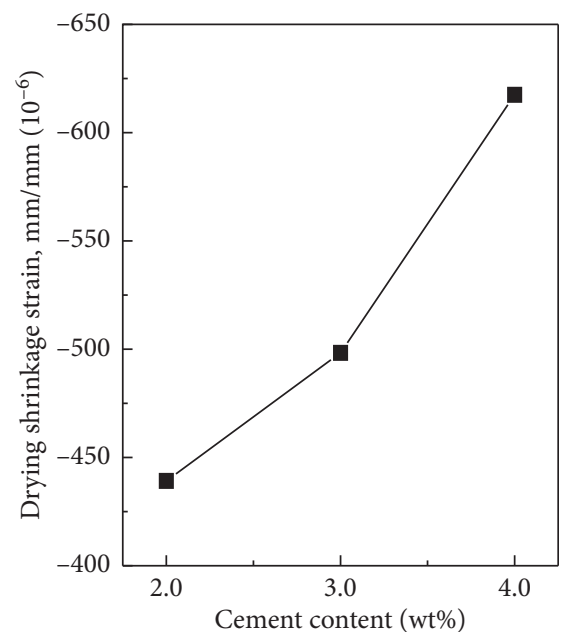

(a)

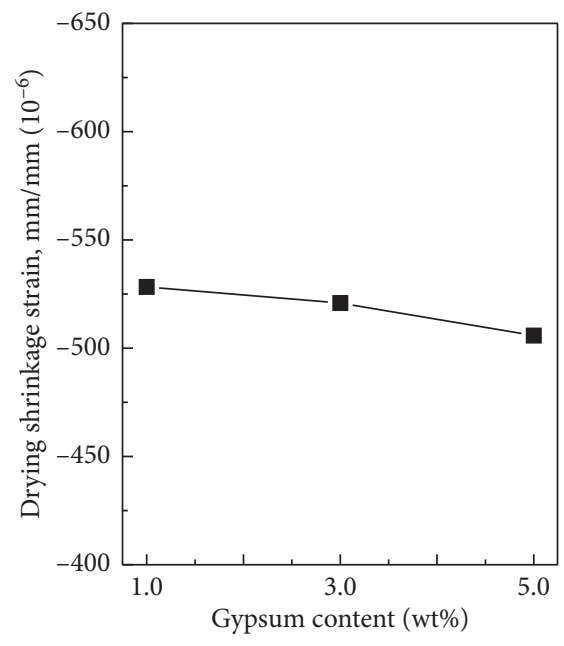

(b)

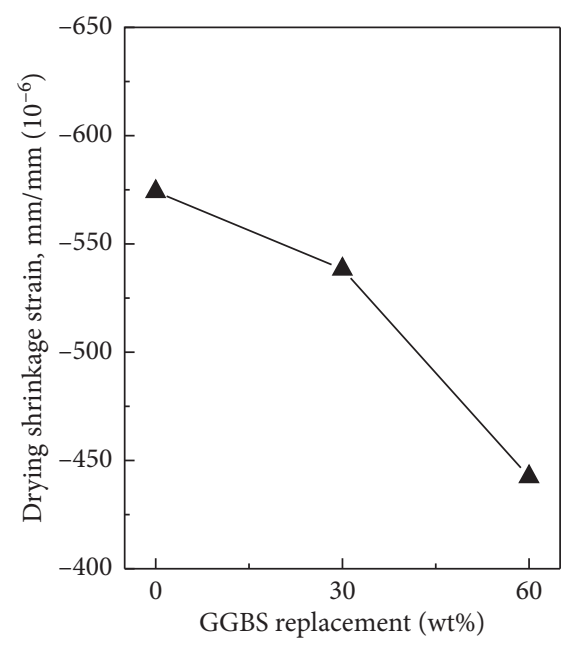

(c)

FIGURE 6: Factor-level trend chart.

(the amount of AFt is proportional to dihydrate gypsum content) [33]. Benefiting from the expansibility of AFt $[24,34]$, the drying shrinkage of CLFBM is compensated. GGBS has higher pozzolanic activity compared with fly ash [35]. As a result, the incorporation of GGBS can promote the above reactions including the formation of AFt. Because of the presence of high content of dihydrate gypsum and GGBS, the sample $\mathrm{N}_{3}$ has the lowest drying shrinkage.

3.3. FE-SEM Analysis. Figure 7 illustrates FE-SEM images and EDS spectra of CLFBM samples. To make a better comparison with the sample $\mathrm{N}_{3}$, the sample $\mathrm{N}_{1}$, which contains the lowest level of dihydrate gypsum (1.0 wt\%) and the equal amount of cement without GGBS, is also selected for SEM analysis. From Figures 7(a) and 7(b), the distinct needle-like products are observed. As presented in Figure $7(\mathrm{e})$, the EDS spectrum of marked region 1 in Figure 7(a) shows that the main elements in the region 1 include $\mathrm{Al}, \mathrm{S}$, and $\mathrm{Ca}$, indicating that the needle-like products are ettringite (AFt) [36]. Obviously, there are more AFt in sample $\mathrm{N}_{3}$ than in sample $\mathrm{N}_{1}$ at 3 days. This is attributed to the use of more dihydrate gypsum and GGBS into sample $\mathrm{N}_{3}$. The AFt can not only compensate shrinkage but also improve the strength. As a result, the sample $\mathrm{N}_{3}$ possesses a higher earlyage strength and lower drying shrinkage, as revealed in Section 3.1 and 3.2.

From Figures 7(c) and 7(d), it is found that there are a large number of C-S-H gels produced from the samples $\mathrm{N}_{1}$ and $\mathrm{N}_{3}$ at 28 days, in which the C-S-H gels can be determined by EDS spectrum $(\mathrm{Ca} / \mathrm{Si}$ ratio in marked region 2 is 1.48) [36]. However, for the sample $\mathrm{N}_{3}$ (Figure 7(d)), more $\mathrm{C}-\mathrm{S}-\mathrm{H}$ gels are formed in the pastes, and the space network structure built by C-S-H gels and AFt is denser as compared with the sample $\mathrm{N}_{1}$ (Figure $7(\mathrm{c})$ ). This can be ascribed to the fact that the activity of GGBS is higher than that of fly ash that is conducive to the more rapid and plentiful pozzolanic reaction. In addition, it is remarkable that the sample $\mathrm{N}_{3}$ 

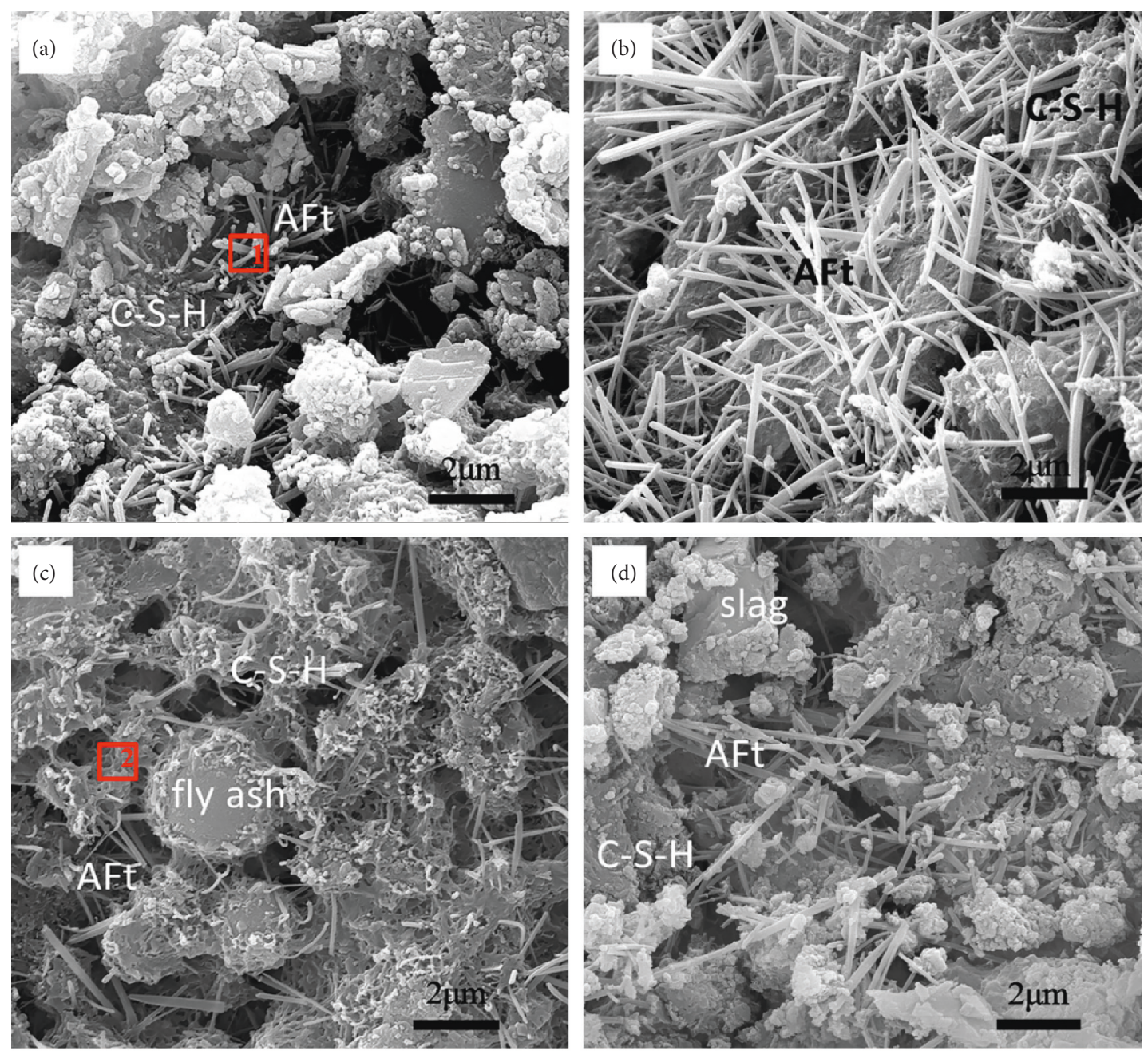

(e)

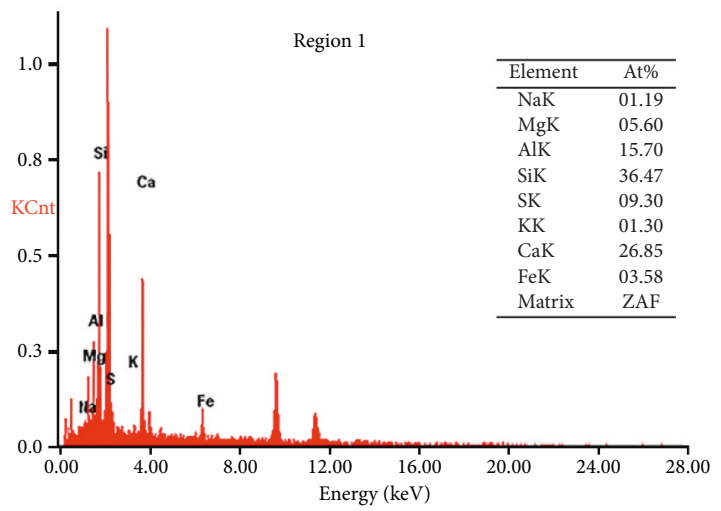

(f)

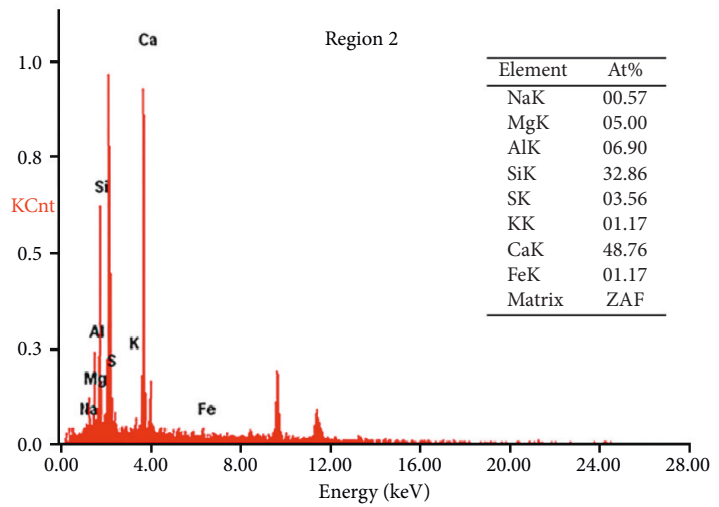

FIgURe 7: FE-SEM images and EDS spectra of CLFBM samples. (a, b) samples $\mathrm{N}_{1}$ and $\mathrm{N}_{3}$ after 3 days, (c, d) samples $\mathrm{N}_{1}$ and $\mathrm{N}_{3}$ after 28 days, and $(e, f)$ the EDS spectra of marked regions 1 and 2.

preserves a relatively large amount of AFt after 28 days, confirming its sluggish drying shrinkage development.

\section{Conclusions}

In this work, the cement-lime-fly ash bound macadam (CLFBM) as novel pavement base materials is prepared by the incorporation of cement, dihydrate gypsum, and GGBS.
In the process of further discussing the performances of CLFBM, the following conclusions can be addressed:

(1) The uses of cement, dihydrate gypsum, and GGBS contribute much to the early-age strength improvement of CLFBM, in which the GGBS replacement is dominant, and the influence of dihydrate gypsum to the early-age strength is nearly the same as that of cement. 
(2) The low cement content and the high level of dihydrate gypsum content and GGBS replacement are considered as the major reason for reduced drying shrinkage.

(3) SEM results reveal that there is a rapid and plentiful pozzolanic reaction between GGBS and lime, and the participation of dihydrate gypsum leads to the formation of a large number of AFt.

(4) The optimized mix proportion of CLFBM is that cement: dihydrate gypsum:lime:fly ash:GGBS: gravel $=2: 1: 6: 5.6: 8.4: 80$. It can be a promising pavement base material because of a high early-age strength and relatively low drying shrinkage.

In the future work, we will focus on the environmental assessment, cyclic behavior, durability, and construction procedures of the modified cement-lime-fly ash bound macadam mixture, and this will provide an important foundation for the application research of the pavement base material.

\section{Data Availability}

The raw data used to support the findings of this study are available from the corresponding author upon request.

\section{Disclosure}

Cheng Ju and Yushi Liu are co-first authors.

\section{Conflicts of Interest}

The authors declare that there are no conflicts of interest regarding the publication of this paper.

\section{Acknowledgments}

The financial support from National Key R\&D Program of China (no. 2017YFB0309901, Provincial funding GX18A025) and the National Natural Science Foundation of China (no. 51578193) for the current research is gratefully acknowledged.

\section{References}

[1] R. Zhou, L. Zhong, N. Zhao et al., "The development and practice of China highway capacity research," Transportation Research Procedia, vol. 15, pp. 14-25, 2016.

[2] L. Jie and H. J. van Zuylen, "Road traffic in China," ProcediaSocial and Behavioral Sciences, vol. 111, pp. 107-116, 2014.

[3] M. M. Disfani, A. Arulrajah, H. Haghighi, A. Mohammadinia, and S. Horpibulsuk, "Flexural beam fatigue strength evaluation of crushed brick as a supplementary material in cement stabilized recycled concrete aggregates," Construction and Building Materials, vol. 68, pp. 667-676, 2014.

[4] Y. Sun and L. Li, "Strength assessment and mechanism analysis of cement stabilized reclaimed lime-fly ash macadam," Construction and Building Materials, vol. 166, pp. 118-129, 2018.

[5] Q. Li, Z. Wang, Y. Li, and J. Shang, "Cold recycling of lime-fly ash stabilized macadam mixtures as pavement bases and subbases," Construction and Building Materials, vol. 169, pp. 306-314, 2018.

[6] J. Xue and Y. Jiang, "Analysis on the fatigue properties of vertical vibration compacted lime-fly ash-stabilized macadam," Construction and Building Materials, vol. 155, pp. 531-541, 2017.

[7] L. XM, "The recycling technology research on the semi-rigid base recycled materials," Master thesis, Chongqing Jiaotong University, Chongqing, China, 2013.

[8] S.-H. Kang, Y. Jeong, M. O. Kim, and J. Moon, "Pozzolanic reaction on alkali-activated Class $\mathrm{F}$ fly ash for ambient condition curable structural materials," Construction and Building Materials, vol. 218, pp. 235-244, 2019.

[9] Y. L., "Construction and quality control key techniques of lime-fly ash base," Master thesis, Shandong University, Jinan, China, 2012.

[10] X. Li, Z. C. Grasley, J. W. Bullard, and E. J. Garboczi, "Irreversible desiccation shrinkage of cement paste caused by cement grain dissolution and hydrate precipitation," Materials \& Structures, vol. 50, no. 2, p. 104, 2017.

[11] D. Snoeck, L. Pel, and N. De Belie, "Superabsorbent polymers to mitigate plastic drying shrinkage in a cement paste as studied by NMR," Cement and Concrete Composites, vol. 93, pp. 54-62, 2018.

[12] X. Wang and Y. Zhong, "Reflective crack in semi-rigid base asphalt pavement under temperature-traffic coupled dynamics using XFEM," Construction and Building Materials, vol. 214, pp. 280-289, 2019.

[13] S. Du, "Mechanical properties and shrinkage characteristics of cement stabilized macadam with asphalt emulsion," Construction and Building Materials, vol. 203, pp. 408-416, 2019.

[14] P. Tikalsky and R. L. Freeman, The Effect of Pouzzolan and Slag on the Resistance of Concrete, The University of Texas at Austin, Austin, TX, USA, 1998.

[15] A. K. Schindler and K. G. Folliard, "Influence of supplementary cementing materials on the heat of hydration of concrete," in Proceedings of the Advanced in Cement and Concrete IX Conference, pp. 10-14, Copper Mountain Conference Resort, CO, USA, August 2003.

[16] S. Kenai, W. Soboyejo, and A. Soboyejo, "Some engineering properties of limestone concrete," Materials and Manufacturing Processes, vol. 19, no. 5, pp. 949-961, 2004.

[17] F. Bellmann and J. Stark, "Activation of blast furnace slag by a new method," Cement and Concrete Research, vol. 39, no. 8, pp. 644-650, 2009.

[18] Z. Yading, W. Cen, G. Xiaojian, and X. Yingnan, "Compatibility of fly ash and slag from circulating fluidized bed boiler for concrete beam," Journal of Wuhan University of Technology-Material, vol. S1, pp. 183-185, 2009.

[19] J. L. Provis, "Alkali-activated materials," Cement and Concrete Research, vol. 114, pp. 40-48, 2018.

[20] J. L. Provis and S. A. Bernal, "Geopolymers and related alkaliactivated materials," Annual Review of Materials Research, vol. 44, no. 1, pp. 299-327, 2014.

[21] G. M. Kim, H. R. Khalid, H. J. Kim, and H. K. Lee, "Alkali activated slag pastes with surface-modified blast furnace slag," Cement and Concrete Composites, vol. 76, pp. 39-47, 2017.

[22] N. Mobasher, S. A. Bernal, and J. L. Provis, "Structural evolution of an alkali sulfate activated slag cement," Journal of Nuclear Materials, vol. 468, pp. 97-104, 2016.

[23] C. J. Shi, "Pozzolanic reaction and microstructure of chemical activated lime-fly ash pastes," ACI Materials Journal, vol. 95, no. 5, pp. 537-545, 1998. 
[24] S. Nagataki and H. Gomi, "Expansive admixtures (mainly ettringite)," Cement and Concrete Composites, vol. 20, no. 2-3, pp. 163-170, 1998.

[25] Y. Thiebaut, S. Multon, A. Sellier et al., "Effects of stress on concrete expansion due to delayed ettringite formation," Construction and Building Materials, vol. 183, pp. 626-641, 2018.

[26] S. Donatello, A. Fernández-Jimenez, and A. Palomo, "Very high volume fly ash cements. Early age hydration study using $\mathrm{Na}_{2} \mathrm{SO}_{4}$ as an activator," Journal of the American Ceramic Society, vol. 96, no. 3, pp. 900-906, 2013.

[27] H.-A. Nguyen, "Utilization of commercial sulfate to modify early performance of high volume fly ash based binder," Journal of Building Engineering, vol. 19, pp. 429-433, 2018.

[28] M. N.-T. Lam, D.-H. Le, and S. Jaritngam, "Compressive strength and durability properties of roller-compacted concrete pavement containing electric arc furnace slag aggregate and fly ash," Construction and Building Materials, vol. 191, pp. 912-922, 2018.

[29] C. Jun and G. Li, "Mechanical properties and drying shrinkage of self-compacting concrete containing fly ash," Romanian Journal of Materials, vol. 46, pp. 480-484, 2016.

[30] J. Pei, J. Cai, D. Zou et al., "Design and performance validation of high-performance cement paste as a grouting material for semi-flexible pavement," Construction and Building Materials, vol. 126, pp. 206-217, 2016.

[31] A. S. A. Al-Hedad, E. Bambridge, and M. N. S. Hadi, "Influence of geogrid on the drying shrinkage performance of concrete pavements," Construction and Building Materials, vol. 146, pp. 165-174, 2017.

[32] G. Sheng, Q. Li, and J. Zhai, "Investigation on the hydration of CFBC fly ash,” Fuel, vol. 98, pp. 61-66, 2012.

[33] A. Mardani-Aghabaglou, O. C. Boyac1, H. Hosseinnezhad, B. Felekoğlu, and K. Ramyar, "Effect of gypsum type on properties of cementitious materials containing high range water reducing admixture," Cement and Concrete Composites, vol. 68, pp. 15-26, 2016.

[34] F. F. Wu, K. B. Shi, and S. K. Dong, "Properties and microstructure of HPC with lithium-slag and fly ash," Key Engineering Materials, vol. 599, pp. 70-73, 2014.

[35] İ Ustabaș and A. Kaya, "Comparing the pozzolanic activity properties of obsidian to those of fly ash and blast furnace slag," Construction and Building Materials, vol. 164, pp. 297-307, 2018.

[36] S. Han, P. Yan, and R. Liu, "Study on the hydration product of cement in early age using TEM," Science China Technological Sciences, vol. 55, no. 8, pp. 2284-2290, 2012. 


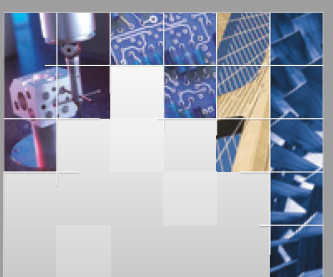

\section{Enfincering}
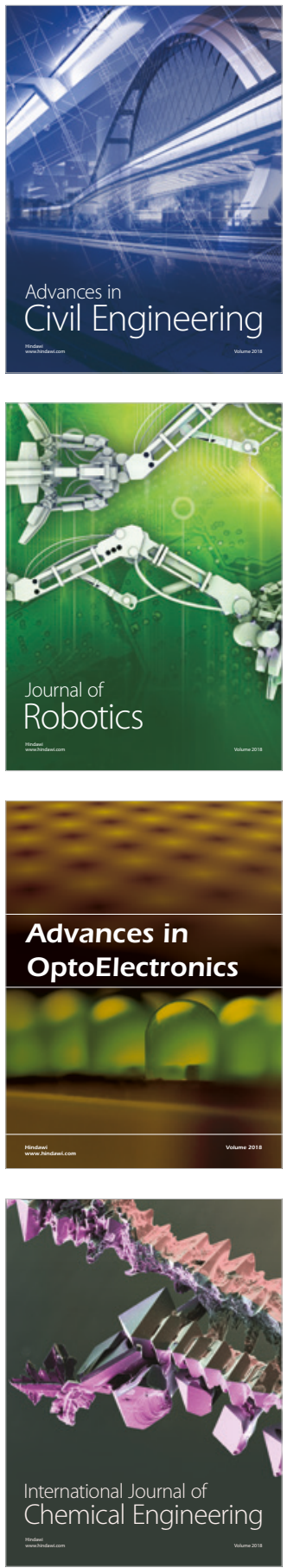

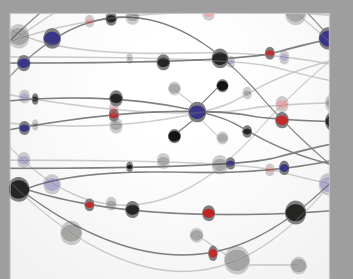

\section{Rotating \\ Machinery}

The Scientific World Journal

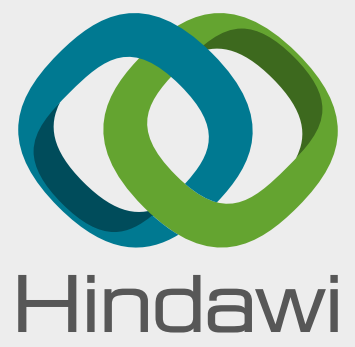

Submit your manuscripts at

www.hindawi.com
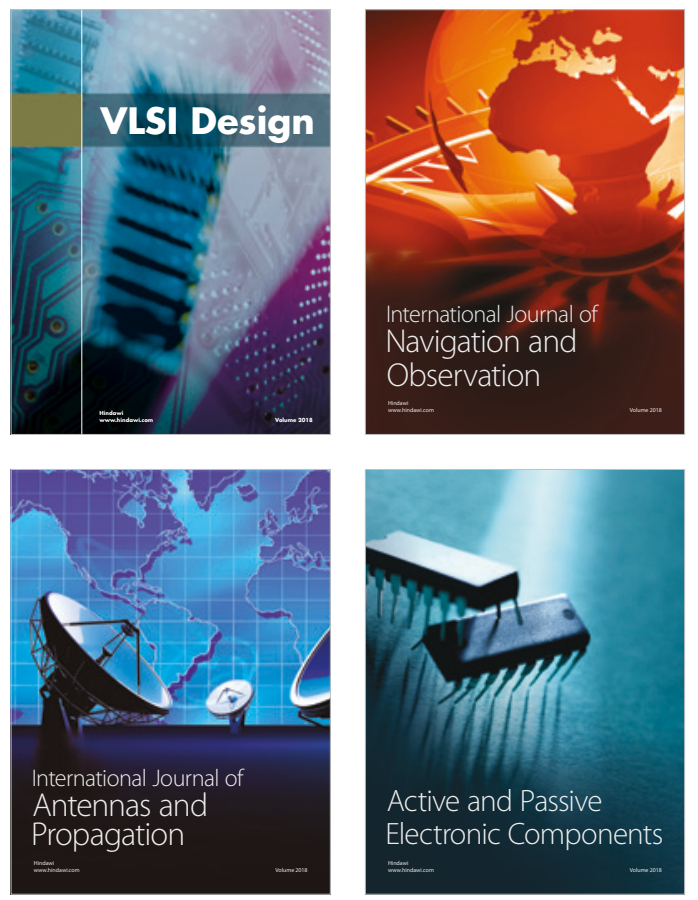
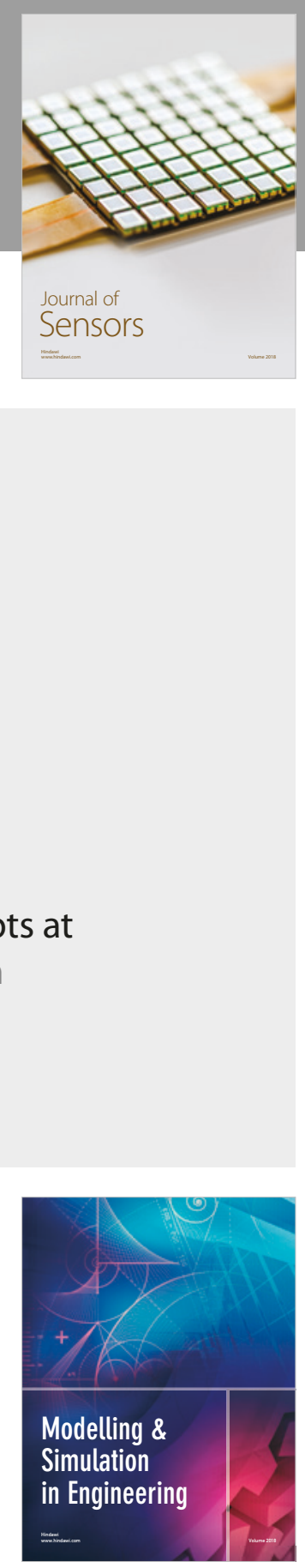

\section{Advances \\ Multimedia}
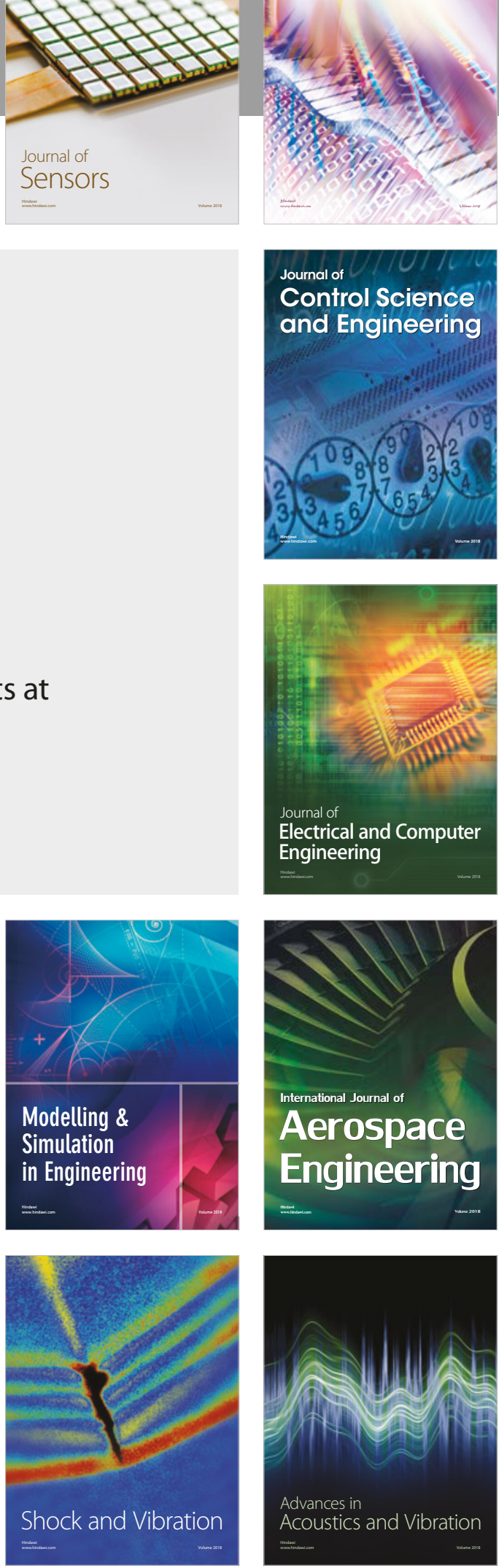